\title{
Lab-scale Technology for Biogas Production from Lignocellulose Wastes
}

\author{
Lukáš Krátký ${ }^{1}$, Tomáš Jirout ${ }^{1}$, Jiří Nalezenec ${ }^{1}$ \\ ${ }^{1}$ CTU in Prague, Faculty of Mechanical Engineering, Department of Process Engineering, \\ Technická 4, 16607 Prague 6, Czech Republic
}

Correspondence to: Lukas.Kratky@fs.cvut.cz

\begin{abstract}
Currently-operating biogas plants are based on the treatment of lignocellulose biomass, which is included in materials such as agriculture and forestry wastes, municipal solid wastes, waste paper, wood and herbaceous energy crops. Lab-scale biogas technology was specially developed for evaluating the anaerobic biodegrability and the specific methane yields of solid organic substrates. This technology falls into two main categories - pretreatment equipments, and fermentation equipments. Pretreatment units use physical principles based on mechanical comminution (ball mills, macerator) or hydrothermal treatment (liquid hot water pretreatment technology). The biochemical methane potential test is used to evaluate the specific methane yields of treated or non-treated organic substrates. This test can be performed both by lab testing units and by lab fermenter.
\end{abstract}

Keywords: ball mill, batch test, fermenter, liquid hot water pretreatment, macerator.

\section{Introduction}

The application of anaerobic digestion technology is rapidly growing at the present time around the world, because of the environmental and economic benefits that it offers. To implement this technology, it is necessary to determine the biogas potential of various types of wastes, which can be found in materials such as agriculture and forestry wastes, municipal solid wastes, waste paper, wood and herbaceous energy crops. These lignocellulose substrates are generally composed of cellulose, hemicellulose, lignin and a wide variety of organic and inorganic compounds. Cellulose and hemicellulose fractions are converted to monosaccharides, which can subsequently be fermented to biogas. However, the inherent properties due to the composite structure make them resistant to enzyme attack. These substrates biodegrade very slowly, and the extent does not exceed $20 \%$ [1]. Pretreatment of biomass is therefore an essential step in order to increase biomass digestibility.

Pilot-plant biogas technology, as presented in Figure 1, was developed in order to evaluate the influence of various pretreatments on biodegrability and on biogas production. The first part of lab technology, the pretreatment section, enables size reduction machines and hydrothermal pretreatment to be used. Afterwards, the treated material can be anaerobically digested, either in a testing unit or in a fermenter, where the quantity and quality of the biogas are evaluated in relation to the energy requirement for the pretreatment that it has undergone.

\section{Biomass size reduction machines}

Comminution technology is an essential part of any biogas plant. The goal of this pretreatment is to disrupt the inherent structure of lignocelluloses, to decrease the particle size and the degree of cellulose crystallinity. In general, the recommended final particle size is $1-2 \mathrm{~mm}$ for effective digestibility. Size reduction increases the total hydrolysis yield by $5-25 \%$, and also reduces the digestion time by 23-59 \%. However, comminution is a very expensive operation that consumes about $33 \%$ of the total electricity demand [2]. Reducing the energy requirement

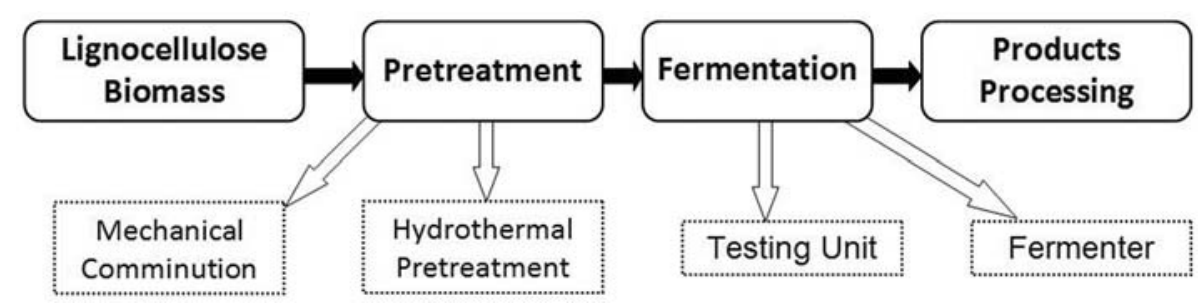

Figure 1: Lab-technology for biogas yield evaluation 


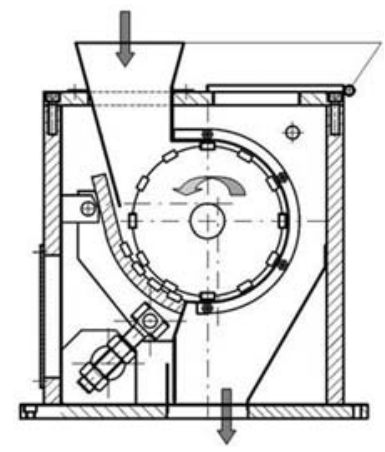

A) Macerator

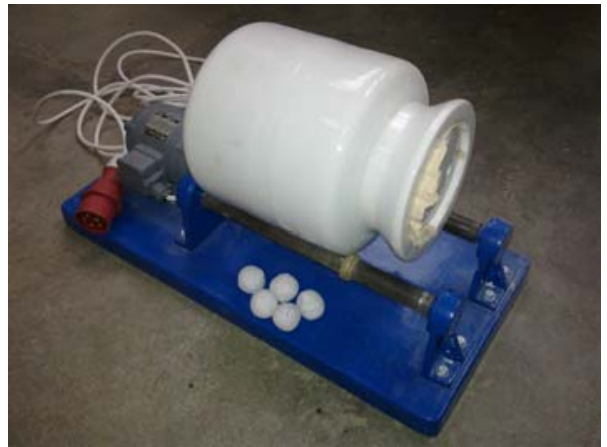

B) Ball mill

Figure 2: Size reduction machines in lab-scale technology

and finding the right solution for biomass disintegration would clearly improve the economics of the whole process.

Knives, hammers, roll mills and colloid mills are widely used for disintegrating biomass. A prototype of a new type of mill called macerator is being tested, see Figure 2A. The idea of this machine is to combine the most efficient milling principles of knives and roll mills. The macerator consists of a single horizontal roll and drum sieve, both with sharp-edged segments. The roll-sieve gap is easily adjustable by screws. In principle, lignocellulose biomass is fed into the gap between the roll and the sieve, where it is soaked in hot water. Due to the high shear and cut forces, the biomass is disrupted and reduced in size, and it passes through the holes in the sieve into the storage vessel. The variable parameters are the amount of biomass, the gap size, the rotational roll speed, the flow rate and the temperature of the hot water. The effectiveness of a macerator is evaluated by the energy demand for comminution, the structure, and biogas tests of the treated material.

The second type of size reduction machine used in lab-scale technology is a ball mill, see Figure 2B. This universal equipment has been found to be a very efficient machine for disintegrating lignocelluloses, and it can be used both for wet milling and for dry milling. The shear and compressive forces disrupt the lignocellulose matrix, and reduce the size and the crystallinity of the cellulose. However, ball milling has also been found to be a time-consuming operation with a very high energy demand for comminution [2]. The effectiveness of a ball mill is determined by the same parameters as for a macerator, see above.

\section{LHW pretreatment technology}

Liquid hot water pretreatment (LHW) is a hydrothermal pretreatment that came into use several decades ago, e.g. in the pulp industry. In this treat- ment, lignocellulose biomass is heated in water maintained by pressure in a liquid state. Above a temperature of $160{ }^{\circ} \mathrm{C}$, lignocellulose matrix begins to be soluble, which means that the nutrients are more accessible for enzymatic attack. The major advantages of LHW are that no chemicals are added and no inhibitors are formed. The reactor is inexpensive to construct because there is low corrosion potential. The effectiveness of LHW depends on the composition and the $\mathrm{pH}$ of the substrate, on the processing temperature, and on the residence time $[3,4]$.

Lab LHW pretreatment technology is used in batch mode. This technology is composed of three main parts: the hydrolyser, the expansion vessel and the ball valve, equipped with a pneumatic actuator, see Figure 3. The hydrolyser is a double-jacketed pressure vessel which can treat biomass up to 8 liters in volume under a maximum processing temperature of $200{ }^{\circ} \mathrm{C}$ and pressure 1.6 MPa. The substrate is indirectly heated by oil circulating in a double jacket. An electric spiral with power $12 \mathrm{~kW}$ is used for heating the oil. The expansion vessel is an apparatus with atmospheric pressure inside, and is used for storing the expanded substrate. This vessel is also equipped with cooling because there is faster vapor condensation after expansion. The third main part, the ball valve, keeps the pressure space in the hydrolyser separate from the atmospheric space in the expansion vessel.

Biomass processing by batch LHW is based on this principle. The hydrolyser is stuffed with a suspension containing lignocelluloses and hot water. The substrate is heated and then, when the processing temperature is reached, it is kept constant for the processing time. Then the ball valve is rapidly opened, and the substrate immediately expands into the expansion vessel. Two products are formed during expansion, i.e. vapor and hydrolyzate. After vapor condensation, the expanded material is removed from the expansion vessel and anaerobically digested, primarily in test units. The effectiveness of LHW is mainly evaluated by the $\mathrm{pH}$, the glucose yield, the structure changes and by biogas tests [5]. 


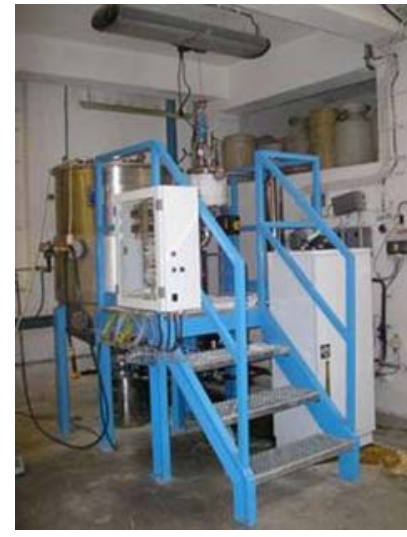

A - equipment

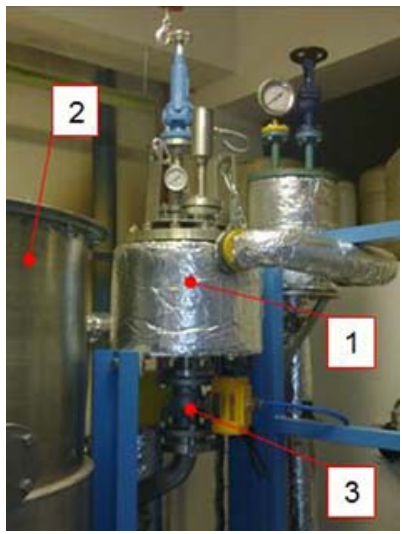

B - apparatus for hydrolysis

1 - hydrolyser; 2 - expansion vessel; 3 - ball valve

Figure 3: The LHW technology in a lab-scale application

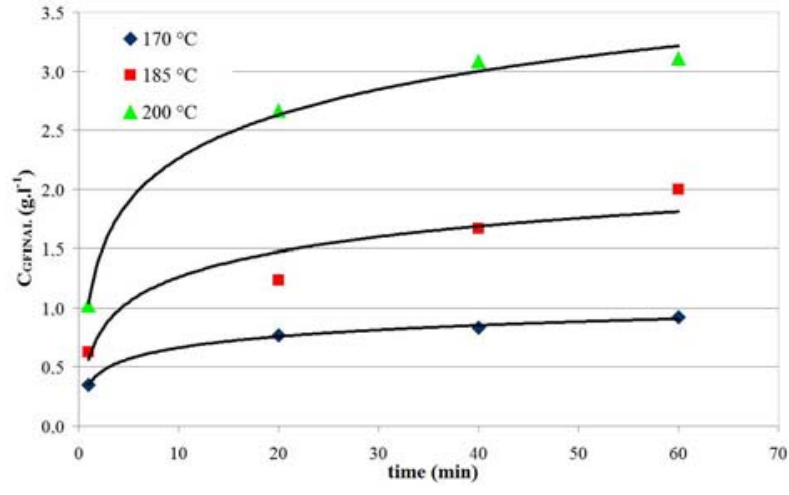

A) glucose yield change

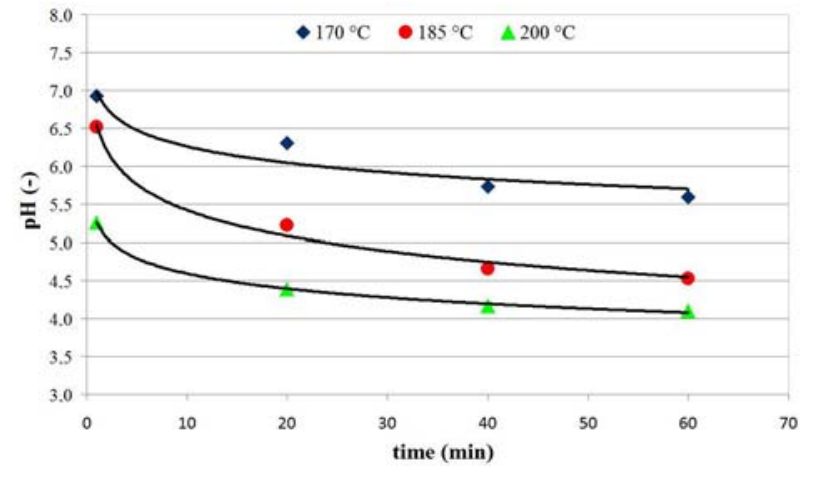

B) $\mathrm{pH}$ change

Figure 4: The dependence of glucose yield and pH on temperature and processing time — wheat straw

LHW technology was used for treating various types of biomass, e.g. wheat straw, silage, office paper and boxboard. In the first experiments, a suspension containing non-disintegrated wheat straw with $5 \%$ by mass was treated. This material was initially incubated at a temperature of $60^{\circ} \mathrm{C}$ to achieve good straw maceration. Then the substrate was filled into the hydrolyser. The initial $\mathrm{pH}$ value was $7.14 \pm 0.05$ and the glucose yield was $0.14 \pm 0.02 \mathrm{~g} \cdot \mathrm{l}^{-1}$. Figure 4 plots the dependencies of the final glucose yield and of the $\mathrm{pH}$ on thermal conditions $170-200^{\circ} \mathrm{C}$ and processing time 0-60 min. The glucose yield (Figure 4A) rises with increasing temperature and time. On the other hand, the $\mathrm{pH}$ values (Figure $4 \mathrm{~B}$ ) fall with increasing temperature and time. Generally, LHW pretreatment causes liquid water under pressure to penetrate into the pores in the biomass. Because of the rapid expansion, liquid water changes phase to vapor, and the associated volumetric change disrupts the substrate, and especially the cell walls. These effects not only increase in glucose yield and cause $\mathrm{pH}$ changes, but primarily increase the biodegradation rate of the biomass. The influences of LHW on the structure of wheat straw and boxboard are shown in Figure 5.

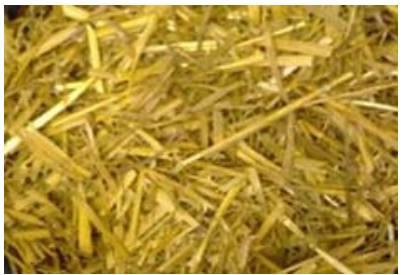

A) straw before

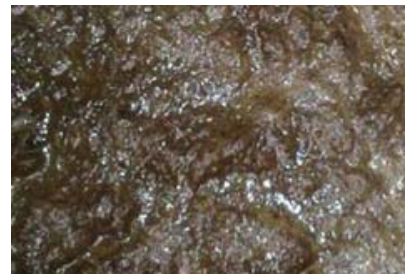

B) straw after

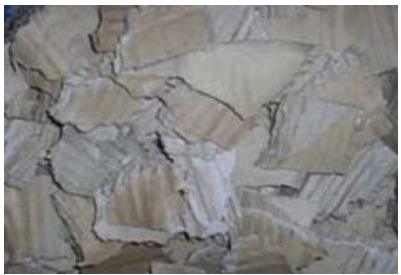

C) boxboard before

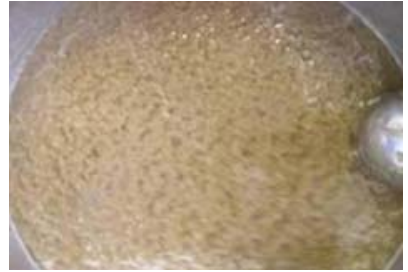

D) boxboard after

Figure 5: Influence of LHW on the structure of biomass — processing parameters $200{ }^{\circ} \mathrm{C}, 20 \mathrm{~min}$ 


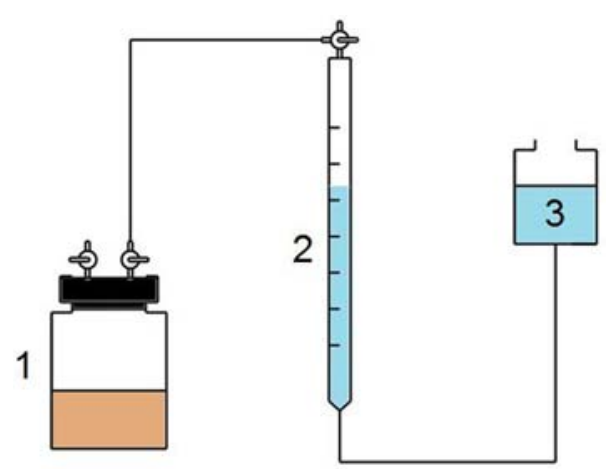

A - scheme of the unit

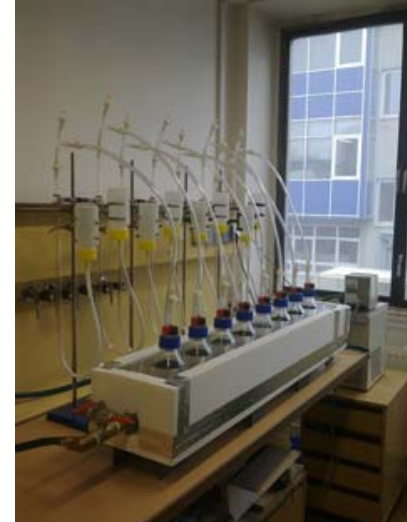

B - lab unit

1 - bottle with substrate, 2 - burette, 3 - balancing bottle

Figure 6: Lab testing unit for investigating biogas yield

In general, substrate pretreated with LHW is more digestible, the amount of biogas is increased, the residence time in the fermenter decreases, and pumping and homogenization are facilitated [5].

\section{Lab-batch tests for an investigation of biogas yield}

A test known as Biochemical Methane Potential (BMP) is widely used for evaluating the anaerobic biodegrability of wastes. Generally, biogas potential can be determined in batch mode or in continuous mode. However, batch systems are more widely used, because they are easier to set up, simpler, and easier to monitor and evaluate. These tests are based on the same principle, i.e. measuring the biogas/methane production. The basic approach is to incubate a waste with an anaerobic inocolum and measure the biogas/methane production [6]. The biochemical methane potential of untreated/treated waste in our technology is investigated with the use of two pieces of equipment: a lab testing unit and a lab fermenter.

First, the lab testing unit shown in Figure 6 is used for primary testing of BMP. Anaerobic digestion experiments are carried out in accordance with European standards VDI 4630 [7] and ČSN EN ISO 11734 [8]. In detail, eight glass batch digesters with a capacity of 0.5 liters are used. These bottles are filled with a mixture of the tested waste and digested sludge from a running biogas plant. Five digesters are used for the replications and the next three bottles for the reference samples. The digesters are incubated under mesophilic conditions at a constant temperature of $35^{\circ} \mathrm{C}$, which is maintained through a water bath. The gas measuring system is based on a simple volumetric method. The biogas produced inside moves to the external burette, where it displaces an equivalent volume of barrier solution from the balancing bottle that provides constant pressure conditions. The amount of biogas is monitored daily, except at the beginning of the test, when the increase in volume is evaluated more frequently. The anaerobic digestion test is considered finished when the volumetric changes are lower than $1 \%$ of the total biogas volume. The quality of the biogas is analyzed by absorbing carbon dioxide $\mathrm{CO}_{2}$ into potassium hydroxide $\mathrm{KOH}$. The evaluation and the characteristics of the tested material and the anaerobic sludge are based on the initial and final $\mathrm{pH}$ analyses, the chemical the oxygen demand $C O D$, the total solid content $T S$, and the total organic solid content $o T S$. In addition to waste in the initial state, there are also investigations of element composition (C, N, S, P, Mg, K) or analysis of fats, carbohydrates, proteins and lignin content.

Secondly, the lab fermenter, as presented in Figure 7 , is used for more detailed BMP tests and especially for scale-up authentication. These tests are carried out according the same processing parameters and rules as in the testing units. The lab fermenter enables an investigation of BMP tests with substrate volume between 20-35 liters. The tested substrate is also indirectly incubated under mesophilic conditions, usually at a temperature of $35^{\circ} \mathrm{C}$ by hot water, which circulates in the external double jacket of the fermenter. Owing to the adjustable pressure difference, the biogas that is produced is moved to the biogas analysis part, see Figure 7B. First, the biogas is cooled to remove the humidity, then the quality and the flow rate of the biogas are analyzed in detail. The evaluation and the characteristics of the waste during the biodegradation process are provided by continually measuring the process parameters in the liquid phase and in the gas phase. In the liquid phase, the total organic carbon $T O C$, the total nitrogen $T N$, the $\mathrm{pH}$, the chemical oxygen demand $C O D$, the redox potential $O R P$ and the temperature are measured. In 


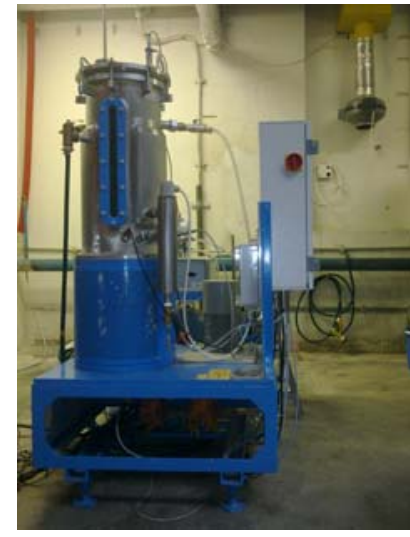

A - equipment

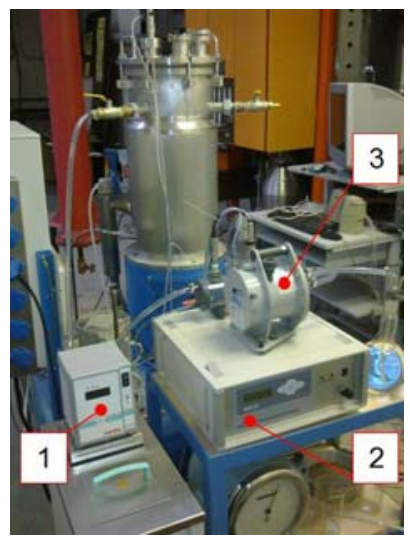

$\mathrm{B}$ - part of the biogas yield investigation 1 - cooling, 2 - gas analyser, 3 - flow meter

Figure 7: Lab fermenter

the gas phase, the pressure, the temperature, the humidity, the amount of biogas and the quality of the biogas are analyzed. The anaerobic process control and monitoring results can be viewed on websites [9].

\section{Conclusion}

Lab pilot plant technology was constructed in order to determine the biogas potential in various types of wastes. This technology makes use of several pretreatment methods aimed at enhancing the anaerobic biodegrability of the substrate and at increasing the biogas yield and the biogas quality. These methods are based on hydrothermal pretreatment or on mechanical comminution.

- The lab ball mill and the new prototype macerator are used for biomass comminution. The energy demands for achieving the required final particle size and structure are under investigation.

- Liquid Hot Water (LHW) pretreatment is used to obtain more digestible biomass. The effectiveness of LHW pretreatment grows with increasing processing temperature and time. LHW pretreatment increases the amount of biogas and decreases the residence time in the fermenter. Homogenization and pumping are facilitated.

- Biochemical methane potential tests can be carried out either by a simple process in a testing unit or by a laborious process in a lab fermenter. The testing units are used primarily for investigating biogas yields, and lab fermenters are used for scale-up investigations.

\section{Acknowledgement}

This work was carried out within the project "The development of environment-friendly decentralized power engineering", No. MSM6840770035, supported by the Ministry of Education of the Czech Republic.

\section{References}

[1] Pandey, A.: Handbook of plant-based biofuels. In CRC Press, New York, 2009, 297 p. ISBN 978-1-56022-175-3.

[2] Krátký, L., Jirout, T.: Biomass size reduction machines for enhancing biogas production. In Chemical Engineering and Technology, 2011, Vol. 34, No. 3, p. 391-399.

[3] Taherzadeh, J. M., Karimi, K.: Pretreatment of lignocellulosic wastes to improve ethanol and biogas production: a review. In International Journal of Molecular Sciences, 2008, Vol. 9, p. $1621-1651$.

[4] Hendriks, A., Zeeman, G.: Pretreatments to enhance the digestibility of lignocellulosic biomass. In Bioresource Technology, 2009, Vol. 100, p. 10-18.

[5] Krátký, L., Jirout, T., Dostál, M.: Laboratorní zařízení pro termicko-expanzní hydrolýzu substrátů při výrobě biopaliv. In 58th $\mathrm{Na}$ tional Congress of Chemical and Process Engineering CHISA 2011, 2011, 10 p. ISBN 978-80-905035-0-2.

[6] Raposo, F., De La Rubia, M. A., Cegrí, F., Borja, R.: Anaerobic digestion of solid organic substrates in batch mode: An overview relating to methane yields and experimental procedures. In Renewable and Sustainable Energy Reviews, 2001, Vol. 11, p. 861-877.

[7] VDI 4630. Fermentation of organic materials characteristic of the substrate, sampling, collection of material data, fermentation tests. ICS: 13.030.30, April 2006, Verein Deutscher Ingenieure. 
[8] ČSN EN ISO 11734. Jakost vod - Hodnocení úplné anaerobni biologické rozložitelnosti organických látek kalem z anaerobní stabilizace - Metoda stanovení produkce bioplynu. ICS: 07.100.20, October 1999, Czech Office for Standards, Metrology and Testing.
[9] Skočilas, J., Dostál, M., Petera, K., Šulc, R.: Měření a regulace provozních parametů laboratorního fermentoru. In 56th National Congress of Chemical and Process Engineering CHISA 2009, 2009, 16 p. ISBN 978-80-86059-51-8. 